\title{
Painting Blood: Visualizing Menstrual Blood in Art
}

\author{
Ruth Green-Cole
}

\section{INTRODUCTION}

The notion of 'gendered blood' (Lupton 1993, 3) is a concept that struggles against patriarchal traditions, which traditionally denigrate and suppress images of menstruation, while European and American art valorize women's bodies as vehicles for male scopic desire. Biologically, blood may not be gendered, but society's values transform it into female, dirty, discharge, abject, shame. Moreover, in Jewish, Christian, and Islamic traditions, menstrual blood is associated with immorality or accursedness due to Eve's temptation of Adam. While Christ's blood is elevated in the Eucharist, as is the blood of heroes lost on the battlefield, 'women with issue' are humiliated or are unspeakable. Earlier art used blood, especially depictions of Christ's blood, in controlled ways to show concepts of humanity, sacrifice, and transcendent spiritual values. Gendered blood in contemporary art is contested and has become an image or medium appropriated from traditional masculinity (and the censorship concerning feminine blood understood as abject) for different subject positions and identities not dealt with in earlier art.

Patriarchal values have kept menstruation as a subject in the margins of art and art history until it emerged in feminist art in the 1970s. Contemporary works discussed in this essay challenge what is acceptable and ask questions about what should and should not be visible. Many menstrual works mean to shock, in true avant-garde fashion, but not needlessly or nihilistically. They are critical interrogations of aesthetic authority and decorum, challenging ignorant and popular beliefs about art's functions, as much as they create visibility and space within art and the public domain for contested values associated with blood. These works may not be easy to look at or decent 
and palatable, as they refuse the requirement that art can only be about traditional prettiness and chaste femininity. Artworks that deal with menstruation in many different ways are important because they work against negative stereotypes and actively revalue gendered blood, showing it in a positive, defiant, or ambiguous light.

Drawing on a feminist reading of Maurice Merleau-Ponty's phenomenology in conversation with work by gender theorist Judith Butler provides a framework to understand gendered performativity. Butler explains that gender becomes constructed through the 'sedimentation' of 'performative acts,' which gradually and through iteration and mutual recognition collectively assemble gender identity. To read menstruation as 'gendered blood' is to recognize the ritualization of difference through cleansing practices, psychoanalytic classification, and other constructs that ultimately affect the position of women. Consequently, visualizing menstruation challenges and exposes ingrained psychological behaviors and categories, because it challenges the valorization in many cultures of the classical, male, sealed body. The 'leaky body' (Irigaray 1985) associated with the weaker sex and its vulnerability, lack of self-control, and natural biological state closer to base materiality is set up in contradistinction. Feminist artists have been important in challenging these kinds of representations of women and creating a space within art and art history for women's voices. Still, Butler challenges gender dualism by claiming that acting aggressively toward patriarchy can reinforce the very notion that feminists are trying to eradicate. Butler elaborates "[Y]et, in this effort to combat the invisibility of woman as a category, feminists run the risk of rendering visible a category which may or may not be representative of the concrete lives of women" (Butler 1988, 523).

In another direction, feminist artists and philosophers such as Luce Irigaray have attempted to be more specific about female phenomenology and to provide positive accounts of such phenomenology, rather than theorizing how gender essentialism is established through social norms. As Irigaray has observed, "[f]luids are implicitly associated with femininity, maternity, menstruation and the body. Fluids are subordinated to that which is concrete and solid" (Irigaray 1985, 113). The continuous concealment of the reproductive body from society (for example, the practice of menstrual etiquette, homebound pregnant women, and the sexualized breast) has created the false assumption that a leaky body is unnatural, and only when it is concealed is the body acting normally. Therefore, the body is seen as something that should be controlled to enable a prescribed representation of self-identity. Menstruation, in particular, has been codified as something uncontrollable that needs to be organized, managed, and contained. ${ }^{1}$

This chapter is developed in two parts: the first briefly traces menstruation in art history, and the second examines visual interpretation and phenomenological approaches to paintings in the contemporary setting that deal directly with this theme. The impetus for retracing representations 
of menstruation through art history is to show how historical and modern art has conceptualized and depicted menstrual blood as a way to discuss how the contemporary artworks examined in this essay are innovative and transgressive. Furthermore, this essay is explicitly centered on how contemporary art challenges preconceived views of menstruation, through an examination of the semiotics of menstrual blood. 'Painting blood' as a medium is discussed in parallel to 'Blood as paint' and is similar to the canonical concept of 'paint as flesh,' as thematized by art historians. For example, artists such as Jusepe de Ribera, Rembrandt, Willem de Kooning, and Lucian Freud all create fleshly paintings with their brushwork. I also address contemporary artists who considered the application of paint to be symbolic of menstrual processes and a comment on masculine painting traditions. Blood performances also provide artistic contexts for how blood has featured as a part of art and public space; I would like to use these performances to situate the relatively under-researched and more particular concept of 'gendered blood' as explored by various contemporary artists.

Controlling, elite, and dominating systems of decorum and aesthetics can be countered by reevaluating the abject, transgressive, and marginalized, which are valorized in contemporary art. The primary intention of this essay is to illustrate how art can transvalue menstruation, thereby disturbing or affecting gender essentialism, and create new and meaningful narratives within visual culture.

\section{Menstruation in Earlier Art History}

Tracing the representation or visualization of menstruation through art history has not been without difficulty as it is not often explicitly depicted. ${ }^{2}$ Nevertheless, menstruation has made its presence felt in painting through indirect and transgressive ways. Modern paintings such as Paul Gauguin's 'grotesque exotic' Parau na te Varua ino (Words of the Devil), an oil on canvas painted in 1892, shows a young Tahitian woman standing naked amidst a tropical garden in front of a masked she-devil. Her posture is that of a woman fallen from grace as she covers her genitals with a white cloth, a symbol of purity. At the feet of the disgraced Eve is a brilliant pink field, encircled by vine roots that are reminiscent of writhing serpents, "leading us to the banks of vermillion flowers that reinforce associations of bloodperhaps menstrual, perhaps that of a passage that has just occurred from virginity into the status of a 'fallen' Eve" (Childs 2003, 178). The modernist artists represented female sexuality from a patriarchal perspective, as a disembodied other that is either weak or writhing in pain. Another example is Marc Chagall's 1910 oil on canvas Birth, which appears to be one of the earliest paintings of a birth scene that openly portrays uterine blood. Gauguin and Chagall's contemporaries Paula Moderson-Becker and Frida Kahlo challenged these male heterosexual images of women. 
While Kahlo never explicitly worked with menstruation as a theme, the image of blood is prevalent throughout her oeuvre, perhaps because she was exposed to many scenes of blood and gore in her life. Kahlo introduces us to the depiction of uterine blood through works such as Henry Ford Hospital and My Birth (Mi Nacimiento), both painted in 1932. Each of these works includes the visual depiction of blood underneath a birthing mother. Painting blood in her personal narratives gives these paintings an emotional clarity and impact that perhaps they would not otherwise have. The black and white lithograph Frida and the Miscarriage (El Aborto, 1932) illustrates a desire to investigate the meaning of her second unsuccessful pregnancy in two years. The lithograph has been divided vertically down the middle to create alternate possibilities, the reality of miscarriage and fantasy future of successful pregnancy. While the painting of blood in Henry Ford Hospital may signify pain and the suffering of miscarriage, the illustration of blood in Frida and the Miscarriage (El Aborto) shows a coming to terms with that suffering, a sign of rebirth and growth.

This theme of birth and rebirth is curiously explored in the later painting of the same year, My Birth, as it confronts the spectator with a frontal presentation of labor. On the surface, the ex-voto painting is an allegorical homage to Our Lady of Sorrows and the loss of her child Jesus. The blood represents loss, and the deity image of Our Lady of Sorrows represents Kahlo's own sorrow. Thus, the painted blood on white sheets partly constructs an iconography of sorrow and loss. The ambiguity is in the title and lack of inscription. My Birth implies that someone in this work is the artist. Is Kahlo the figure giving birth or the baby being born? Or, is it a double maternal failure: the death of Kahlo's own mother two months after her miscarriage? The infant appears to have Kahlo's iconic monobrow; perhaps it is a self-rebirth? The intended meaning of the loss of Kahlo's mother and child could mean that all she can now give birth to is endless self-portraits. Yet it is an ex-poto, one that gives thanks for survival. Kahlo's paintings and their vivid depiction of uterine blood bear witness to her pain and suffering.

\section{Seventies Feminism and Art}

The feminist art that developed in the late 1960s, through the 'second-wave' of feminism in the United States and England, was heralded by a long history of feminist activism. There were two distinct approaches at the time. New York City had a substantially fixed gallery and museum system, and women artists such as Nancy Spero and Louise Bourgeois worked mainly for equal representation in art institutions. This was in contrast to California, where women artists such as Judy Chicago and Miriam Schapiro concentrated on creating a different, separate space for women's art, rather than fighting an entrenched order of male-dominated artists, gallerists, and critics. Feminist artists often combined aspects from various art movements, 
including conceptual art, body art, performance art, and video art into works that exhibited a message about women's lived experience and the need for gender equality, often in very physical and visceral ways. Performance art in particular, because it is created on a very intimate level and often with no distinction or separation between the artist and artwork, became difficult to ignore or consign to the margins.

During the early 1960s, some years before the growth of an organized feminist movement in the visual arts, Fluxus artists Shigeko Kubota and Carolee Schneemann positioned their bodies in, and as, their art. They employed the modernist language of abstract expressionism, but in contrast to its patriarchal expectations. These artists were "interested in debunking or overthrowing modernism because of its supposedly reactionary desire to ensure the artist's presence" and its dismissal of body art projects. The female artist's body became a gesturing, expressive body, a mode of projecting nonconformity, suffering, activism, and excess, "as a way of laying claim to 'being' itself" (Jones and Warr 2012, 21). As Kubota said in her Video Poem (1968-76), “I, a woman, feel, 'I Bleed, therefore I am' (Stiles and Selz 2012, 504)."

Kubota's Vagina Painting (1965), Schneemann's Interior Scroll (1975), and Ana Mendieta's Body Tracks (1974) (as well as subsequent homages by Schneemann and Nancy Spero to the aforementioned Body Tracks) show a spatial and metaphorical use of paint as gendered blood through female expression. In a subjugation of Abstract Expressionism, artists like Kubota used an intermingling of painting and performance to demonstrate that women have a voice within art making and to demarcate space for women as (re)action against the dominant ideologies surrounding painting. Artworks such as Kubota's Vagina Painting and Schneemann's Meat Joy (1964) destabilized the conventions of art history and criticism, paving the way for widespread feminist art making.

Judy Chicago's depictions of menstruation, Red Flag (1971) and Menstruation Bathroom (1971-2), have become some of the most documented artworks visualizing menstruation in popular culture. Similarly, Schneemann's Interior Scroll-the canonical performance of vulvic spacehas now become the ultimate anticlassical-sealed body presentation, referencing menstruation without the semiotic of blood. There were, however, other important blood prints from the seventies, such as Schneemann's BLOODWORK DIARY (1972) and Judy Clark's Menstruation (1973), as well as occasions of menstrual performance. Catherine Elwes' Menstruation I and Menstruation II (1979) were performances of horizontal blood inscriptions created through processes of bleeding, drawing, and writing. Through performance, bloodletting, or painterly gestures incorporating a trace of the body, we can also include Marina Abramović, Gina Pane, Ana Mendieta, and later Orlan. These artists all inscribed their blood as gendered, ultimately demarcating a space for contemporary visualizations of menstruation. 
Subjects such as sexual violence, menstruation, childbirth, media images, and abortion were high on the agenda of American feminist artists working in the 1970s. Judy Chicago determined, "I just know that I wish to base my artmaking entirely on female reality - using objects, items, references that relate to beauty parlors, makeup, menstruation, victimization" (Levin 2007, 179). Chicago refers to menstruation as one of the many female 'issues' that is worthy of individual attention. Chicago's representation of a used tampon in her photographic lithograph, Red Flag (1971), is typical of the American feminist objective in the 1970s. She elaborates,

I wanted to validate overt female subject matter in the art community and chose to do so by making "Red Flag" as a handmade litho[graph], which is a 'high art' process, usually confined to much more neutralized subject matter. By using such overt content in the form, I was attempting to introduce a new level of permission for woman artists. It really worked. (Delaney, Lupton, and Toth 1976,275 )

Chicago's lithograph Red Flag initially conjured frightful visions of a bloodied penis, which is typical of Freud's 'phantasy' springing to life. Those who consider the image more carefully would note the silhouette of a vulva and blood-soaked string as indicative that the image shows Chicago in the act of tampon removal, rather than a partially castrated penis. Chicago commented that such confusion was "a testament to the damage done to our perceptual powers by the absence of female reality" (Bobel 2010, 47; Rosewarne 2012, 168). The practice of 'menstrual denial' was exactly what Chicago was trying to abolish. In hindsight, the notion that the lithograph is something other than what it depicted, a blood-soaked tampon, seems strange. However, it seems logical to posit that this might have been one of the earliest images that depicted this routine action, one that women know intimately, yet which is visually absent in many Euro-American cultures (Delaney, Lupton, and Toth 1976, 275).

The significance for Red Flag, according to American feminist art historian Arlene Raven, was that "the title, hidden language for menstruation and revolution, would also be hidden information to most men and even some women. Nevertheless, the directness and strength of the visual image elicit immediate, powerful reactions" (Levin 2007, 183). These reactions were a case in point for what Chris Bobel discusses as 'menstrual activism' (2010). The purpose of such 'abjectifying' projects was to "rectify some glaring omissions in art" (Rosewarne 2012, 168) and to bring menstruation out of the "great medicine cabinet of American culture" (Rosewarne 2012, 164). The reaction evoked by Red Flag transferred to Chicago's next project, Menstruation Bathroom, for the collaborative installation Womanhouse (1972) with feminist artists Miriam Schapiro and Faith Wilding, among others. ${ }^{3}$

While the emphasis in the 1970s was on constructing gender equality, the concern now tends to be avoiding gender essentialism so that women can 
think of themselves outside of patriarchally determined dichotomies of same/ other, male/female, and subject/object. It is worth considering whether the subject of menstruation in art is situated within these two phases of feminism differently. In the seventies, it was important to draw attention to (and be proud of) issues and topics, such as menstruation, that had been swept under the rug. Looking forward, has anything changed substantially? Do artists dealing with menstruation within contemporary art have something new to say, or are they still struggling to get patriarchal societies to own up to their prejudices surrounding menstruation? What contribution will visualizing menstruation make to social change? The following section discusses a range of painters and printmakers who utilize menstruation or menstrual blood as a medium to transgress boundaries and challenge normative assumptions about the menstrual cycle.

\section{Painting Blood}

Paint has the capacity to evoke the body's viscera, both internally and externally. Curator Mark Scala proclaims that paint becomes a 'human paste,' as it allows painters to capture the human qualities of the body, revealing something of the subject's psyche and also of their own (Frist Art Museum 2009). 'Paint as flesh' has a long tradition that reaches back to the Renaissance. Referring to the Spanish artist Jusepe de Ribera (1591-1652), art historians have written about his "marks and lines in wet paint creating topography of human flesh as a mirror of the human spirit" (Held and Posner 1971, 85). Many modern and contemporary artists fall along the art historical continuum of 'paint as flesh.' We see this in Bacon's visceral rendering of meat and flesh, as well as in Jenny Saville's truncated portraits of butchered meat and her plastic surgery-inspired portraits, with paint so thick that the skin appears almost translucent. All this fleshiness can be achieved with paint. Flesh and paint are configured within a unified semiotics in painting, and can be extended to include 'blood as paint,' as seen in Rembrandt's Rape of Europa (1632), which enacts blood as paint within Europa's dress. Paint as blood and blood as paint can be employed metaphorically and exchanged or creatively elided.

Kubota's Fluxus performance, Vagina Painting, mentioned above, took place right after she moved from Japan to New York. It was performed at the Perpetual Fluxus festival in 1965. Kubota informed her audience that she would be using her vagina to paint. In fact, the paintbrush was attached to her underwear but was made to look as though it was directly inserted in the vagina. Upon dipping the paintbrush into a pail of red paint meant to invoke menstrual blood' (Butler 2007, 256), Kubota crouched over large rolls of white paper spread out on the floor and pushed down against the paper to make marks. She repeated this gestural, painterly process several times, as the brush dried regularly, in order to cover the roll of white paper. Painting 
in a horizontal direction above the painting surface is a gesture to the 'eastern calligraphic tradition' (Yoshimoto 2005, 178), as the individual movements painted with the brush created red script-like marks on a crisp white background.

Art Historian Kristine Stiles asserts that Kubota's performance "[r]edefined Action Painting according to the codes of female anatomy" (Stiles 1993, 82), insofar as Jackson Pollock can be considered to have "masturbated' and 'ejaculated' paint upon a horizontal un-stretched canvas. Vagina Painting makes a comment on the tradition of masculine Action Painting, by trespassing on patriarchal aesthetics. Stiles adds that " $[\mathrm{t}]$ he direct reference to menstrual cycles seems to compare the procreation/creation continuum lodged in the interiority of women with the temporal cycles of change and growth she experienced in her own art and life after moving from Japan to the United States" (Stiles 1993, 82). Her performance piece made both female and male viewers feel a sense of discomfort. The female spectators voiced concerns about Kubota's paintbrush 'coming out of her vagina' and empathetically discussed how uncomfortable she must have been. Male viewers were faced with symbolic references to menstruation through the use of red paint. Kubota draws a parallel "between human procreation and artistic creation using the vagina as the artistic medium" (Yoshimoto 2005, 179). Not only does Kubota redefine an artistic process, but she also creates within a space of otherness on the margins of Abstract Expressionism. Kubota's spatial art practice blurs the boundaries of masculinist approaches to artmaking. Vagina Painting is a cyclic expression of women's difference that plays upon the semiotic between vagina as sexual organ and menstruation. This work builds on Irigaray's 'counter-penis' argument, an action toward the increasingly difficult situation of making work in a patriarchal paradigm.

The iconography of blood on white fabric recalls an old trope that has become synonymous with 'menstrual shame.' Referring back to Kahlo and Kubota, nothing stands out more than the sight of a bloodstain on white cloth. Nonetheless, menstrual symbolism is something that Irigaray (1980, 71) celebrates:

I love you: body shared, undivided. Neither you nor I severed. There is no need for blood split between us. No need for a wound to remind us that blood exists. It flows within us, from us. It is familiar, close. You are quite red, and still so white. Both at once. You don't lose your candor as you become ardent. You are pure because you have stayed close to the blood. Because we are both white and red, we give birth to all the colors; pinks, browns, blonds, greens, blues . . . For this whiteness is no sham, it is neither dead blood nor black blood. Sham is black: it absorbs everything, closes up and tries to come alive, but in vein ... The whiteness of this red appropriates nothing. It gives back as much as it receives, in luminous mutuality. 
Irigaray uses 'red' and 'white' to critique color associations of passion and purity and uses them to create a locus where 'opposites' may coexist at once, but in a new way. The combination of red blood on a white background constitutes a reference to menstruation as it signifies menstrual blood that cannot be contained.

\section{Gendered Blood in Contemporary Art}

Sarah Maple is a provocative contemporary British painter, photographer, and performance artist of Iranian and English descent, who uses the symbolic power of blood on white fabric to create a painting that transgresses social and cultural borders. Maple, in her self-portrait Menstruate with Pride (2010), brazenly confronts the taboo of menstruation. The three-paneled painting fits within a broader theme of women and shame, where she uses herself as the subject of humiliation to circumvent patriarchal values in society and, in particular, her Islamic religion. By employing the triptych convention on a two-dimensional support, she underscores the connection to traditional religious altars. Because of her challenge to traditional notions of religion, Maple has been the subject of death threats and protests about her art, and her exhibitions have been vandalized. Maple asserts that her work is a product of a mixed religious upbringing and is not intended to insult, but rather to provoke thought. Curators have continued to exhibit her work despite the "attack on freedom of expression" (BBC 2008). Maple, in an artist statement, narrates the purpose of her art in the third person, "Maple explores the phallocentric regions of pop-culturally transgressive and transcendental phenomena. Her endeavours strike fear at the status quo by erecting an almost architecturally [sic] notion of symbolic terror thus rendering the seemingly un-flinched established order limp with its own theoretically paradoxical flaccidity. She splices binarisms in a comely, fearsomely and castrative manner." This "feminist quasi-conceptualisation" (Maple 2010) makes a statement about how women are perceived and presented from a unique lived experience of dual heritage, which can often expose contradictions.

Maple's painting portrays a semicircle of people enclosing her as she looks out of the canvas toward the spectator, daring us to make a judgment. The onlookers in the painting are of mixed gender and ethnicity, although there is not a diverse representation of age. One child is present with her eyes shielded by her mother's hand, which is an effort to protect the young girl from seeing the inevitable. The group blocks Maple's path, giving her nowhere to go; they lean away in horror. The focus of fear and ridicule is the menstrual stain upon her white dress. Her body transgresses social norms. Maple's personal space is crowded and therefore compromised. Despite the outburst of disgust that surrounds her, the artist raises her fist to salute the viewer, presenting the symbol of resistance and unity, the opposite of a white flag of surrender. Maple challenges the collective belief that menstrual blood 
is revolting as socially constructed. Women are taught to be ashamed when blood leaks on to one's clothing; Maple is saying that this normative perspective is prescribed and unjust. Instead, women should stand proud and menstruate (Fig. 57.1).

Reproduction is represented by the womb-like lamppost in the background, hovering above Maple's head like a female deity, symbolic of a uterus. Maple has taken care to paint a variety of emotions. In the female subjects, expression ranges from humiliation to empathy, objectification, and menophobia, while the male subjects show predominantly terror and disgust. For the group, Maple ceases to be a person with feelings as she is subjected to this public display of judgment; even the monkey is laughing. As in a history painting, Maple includes a self-portrait in assistance; on the right and to the rear of the group, she is wearing the Muslim hijab. Even though her mouth is covered she is smiling with her eyes. Maple's duplication comes from an earlier work, the provocative c-type print, Sharia Law the Third (2009), a photographic self-portrait holding a blue book inscribed in gold foil, "Sharia The Islamic Law." The joke is not on the artist but on the crowd surrounding her.

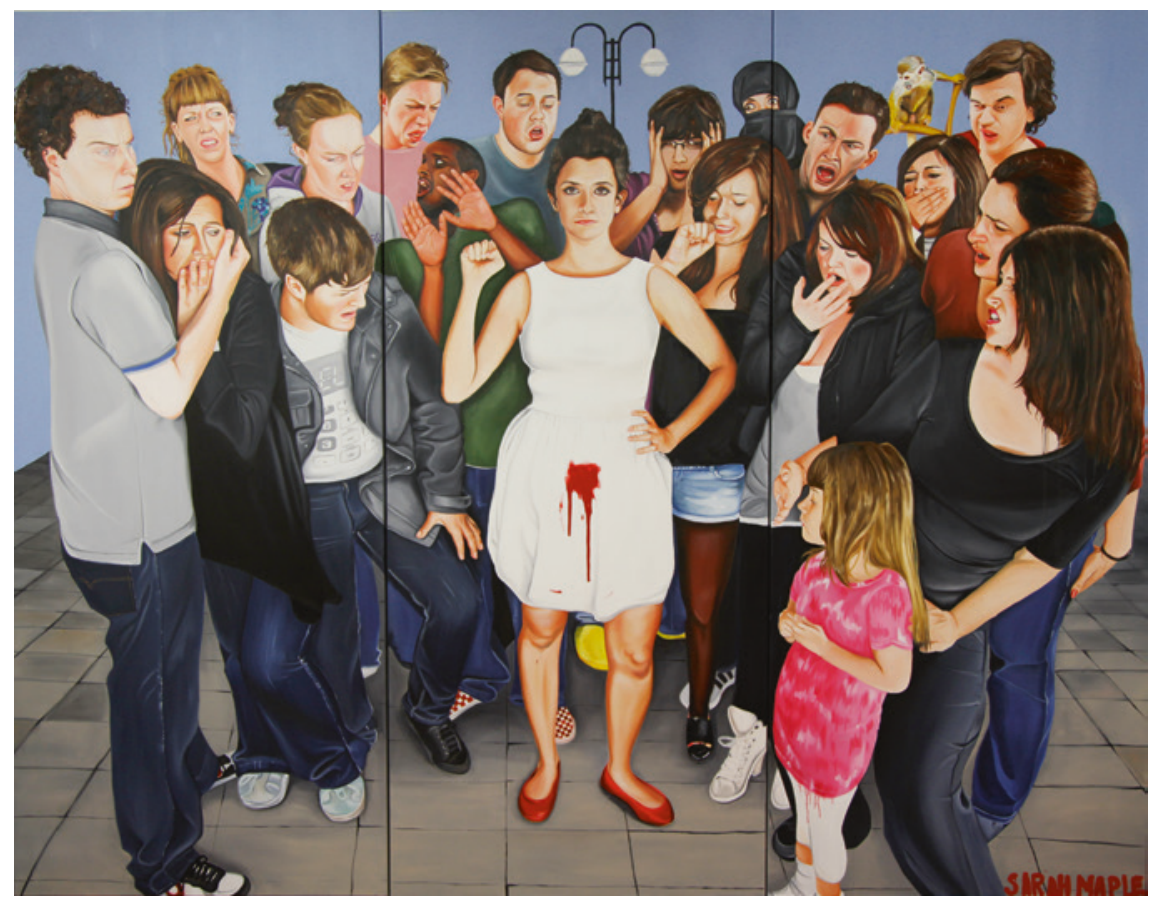

Fig. 57.1 Sarah Maple, Menstruate with Pride, oil on canvas, $275 \times 275 \mathrm{~cm} 2011$ (Credit: Sarah Maple) 
Maple is a menstrual activist making a humorous comedy about the universal prejudice of 'embarrassing' leakiness.

Maple's paintings draw inspiration from Kahlo, who also regularly used the self as a subject to depict personal, societal, and cultural injustices. ${ }^{4}$ However, her application of paint is akin to that of muralist Diego Rivera, firmly placing her painting in conversation with political and protest murals. With a twist of pop realism, she employs 'tongue-in-cheek' humor to balance the political protest in a bid to make visible the ridiculous nature of taboo. To give an example, Maple's signature is suggestive of blood-dripped letters from a horror movie, as well as tagging or graffiti art, which links back to the suburban scene of this painting. Menstruate with Pride is conventional in the sense that it adheres to the rules of painting. Maple opens the space of the painting through a one-point perspective to draw the viewer into the scene. She also uses foreshortening effectively to give the characters dynamism, and so the audience senses their abjection in association with menstrual blood.

Many societies associate menstruation with a time of emotional instability, discomfort, and annoyance, resulting in a general consensus that both women and men loathe menstrual blood. Interestingly, creative women such as Louise Bourgeois have referred to menstruation as being "a blessing" and the "best, most creative time," which aligns female fertility with artistic creation and generation (MacMillian 2008, 75; Coxon 2010, 110). Although none of Bourgeois' works directly reference menstruation, except perhaps one anatomical drawing, her paintings depicting sexuality, motherhood, and birth use the color red in a way that suggests menstrual blood. For Bourgeois, red conveys a multitude of meanings:

Red is the colour of blood

Red is the colour of paint

Red is the colour of violence

Red is the colour of danger

Red is the colour of shame

Red is the colour of jealousy

Red is the colour of grudges

Red is the colour of blame. (Bernadac 1998, 40; Coxon 2010, 22)

Bourgeois' menstrual iconography is extensive, seen vividly in many works from the 2008 'Nature Study' exhibition on display at the Edinburgh Royal Botanic Gardens. Her blood-red gouache drawings are complemented by a selection of botanical illustrations that provide a dialogue concerning nature, sensuality, and reproduction. In works like Birth (2008), Bourgeois fluidly depicts the separation of mother and child. Both figures are painted blood red, composed with a viewpoint that suggests a doctor's examining gaze over splayed legs and a baby descending into this world. In The Couple (2007), the red wispy lines appear as parallel bloodstains linked together by an umbilicus. The work is watery and bloody, abstract yet figurative; they are bloodstains 
personified. We search for some kind of facial recognition within these fluid forms and see two figures emerge standing opposite each other, male and female, their sexual organs reaching toward each other.

'Paint as blood' becomes literal when artists begin to use human blood as a medium. As early as 1973, Judy Clark created a test strip of menstrual bloodstains. She often uses "paint as a stain or sense of seepage" as it allows her to "bring out aspects of human experience that can be hidden or unrecognized" (Clark 2014). Clark's work on paper is laid out on a formal grid, each square holding a circular, organic stain. Each bloodstain has layers, which show that the stain has dried at different rates. This work on paper was produced for a show called Issues at Garage Art Ltd, London, where it accompanied other works that used alternative substances from the home including dust, a collection of human hair, and a collection of used plasters, complete with old skin particles, blood, and pus.

Jess Von der Ahe uses blood as a medium for painting and drawing. She mixes it with resin for a body of painterly drawings she calls drolleries, also known as 'grotesques.' These hybrid forms are usually a combination of animals, or of humans and animals. Drolleries are found in the margins of illuminated manuscripts featuring the words of God, and usually have a thematic connection with the text. They were popular around 1250 and look similar to creatures found in Hieronymus Bosch's painting The Garden of Earthly Delights (1503-4). Von der Ahe's complex droll, Adam and Eve (After Lucas Cranach the Elder) (2005), is a composite work of naked human figures all converging to create the form and detail of Adam and Eve. The erotically positioned figures come together as a mass of bodies in an orgy within the internal frame of the first woman and man. Von der Ahe's drawing simply titled 9-5-05 (2005) draws parallels with Bourgeois' The Couple (discussed above). The difference is that in Von der Ahe's version the woman is part wheel and the male figure is holding a flower.

Menstrual blood is a potent symbol of inner fluid that brings forth life, and therefore the image is a powerful claim for women's importance to the human race. Using this fluid as a medium in painting and printmaking makes this potency more literal. Perhaps the ultimate transgression is the use of menstrual blood as medium, as it is a step further than representation. Blood as a substance for painting complements the notion of painting as autobiography or personal expression. Blood, human essence, is thus impregnated into works by Von der Ahe and Clark. The use of actual blood on paper implies blood flowing out of control. The bloodstains in Clark's work are clinical; while they appear organic, they are controlled by the formation of the grid. Von der Ahe's stained drawings, on the other hand, are more intuitive; they are surreal figures morphing from autonomous drips of menstrual blood. They are blood drawings of pure psychic automatism. 


\section{CONCLUSION}

Menstrual blood, which is gendered blood, has moved from the margins into the public realm of art to challenge dominant ideologies, prejudices, and fears. As a result, menstrual blood and themes of menstruation are now visible within contemporary art and are being used productively to question gender essentialism. It is important to keep in mind that there is not one right or correct way to understand what menstruation, menstrual blood, and taboo mean. Nevertheless, it is essential that artists should be allowed to analyze and expose how traditional structures of power can make people feel vulnerable and ashamed. In very diverse and personal ways, the artists I have discussed in this essay share this common aim. Some artists, such as Chicago, Abramovic, and Mendieta, use their art to critique how menstrual blood is made into gendered blood and associated with a stereotype of the weaker and inferior sex. This biological determinism remains unchallenged if assigned to the margins of the non-visible. Thus, their art functions as a social critique of gender essentialism joined to biological essentialism. Some artists, such as Kubota, Maple, and Von der Ahe, go further and celebrate menstruation in their art as a way to turn stigma and shame into transgressive and creative acts. This causes some conflict, the kind characterized by the different traditions of feminism indebted to Butler and Irigaray. While Butler vehemently opposed gender essentialism and saw gender as a social and cultural construct assigning negative traits to women, Irigaray was content to accept some of these traits and celebrate them as a 'female imaginary,' a way of transgressing against patriarchy. It could be argued that this tension continues to exist in the multiplicity of approaches to menstruation in art. It is crucial that such discourse be aired in public, made visible, and divested of any historical or habitual residues of shame or deference to models of decorum and femininity.

This chapter analyzed how artists have used paint to signify or stand in for blood as a challenge to the decorum of modernist formalism, which conveniently erased women's issues. It has made the important contribution of situating menstruation within the discourse of art history. While works of art made with menstrual blood and about menstruation have been created by feminist artists as early as the mid-sixties, this women's 'issue' has never been exclusively researched outside of larger projects on abjection, performance, or feminism. This research and the contemporary artworks that it engages with have the potential to put a marker in the sand, to say no longer will women hide in the menstrual closet, no longer will women be made to feel ashamed by human biological processes.

\section{Notes}

1. The contraceptive pill is a way that women can control menstruation in the same sense that waxing is a way to control unwanted body hair. It allows women to emulate this notion of containment of the classical sealed body. 
2. For an in-depth study of menstruation in early modern England see, Sara Read, Menstruation and the Female Body in Early Modern England (2013).

3. For a list of collaborator names, visit the Womanhouse Official Website, http://womanhouse.refugia.net/.

4. This can be seen in Maple's painting, If I loved you it was because of your hair. Now that you are without hair, I don't love you anymore (2010), oil and acrylic on canvas $(170 \times 190 \mathrm{~cm})$. This painting is a portrait of Britney Spears in homage to Kahlo in her Self Portrait with Cropped Hair of 1940, oil on canvas $(40 \times 27.9 \mathrm{~cm})$.

\section{REFERENCES}

BBC. 2008. "Muslim Artist Gets Death Threats." Last Modified 31 October 2008. Accessed January 25, 2014. http://news.bbc.co.uk/2/hi/uk_news/england/london/7701168.stm.

Bernadac, Marie-Laurre. 1998. Lonise Bourgeois: Recent Work. Exhibition Catalogue. London: CAPC Musee d'art Contemporain de Bordeaux/Serpentine Gallery.

Bobel, Chris. 2010. New Blood Third-Wave Feminism and the Politics of Menstruation. New Brunswick, NJ: Rutgers University Press.

Butler, Cornelia H., et al., 2007. WACK!: Art and the Feminist Revolution. Los Angeles: Museum of Contemporary Art; Cambridge, MA.

Butler, Judith. 1988. "Performative Acts and Gender Constitution: An Essay in Phenomenology and Feminist Theory." Theatre Journal 40 (4): 519-31.

Childs, Elizabeth C. 2003. "Eden's Other: Gauguin and the Ethnographic Grotesque." In Modern Art and the Grotesque, edited by Frances S. Connelly, 175-92. New York: Cambridge University Press.

Clark, Judy. 2014. “Gallery Statement.” Accessed January 21, 2014. http://www. judyclarkartist.co.uk/gallery.php?page=gallery.

Codreanu, Florina. 2009. "Dynamics of Blood in Frida Kahlo's Creation.” Bulletin of the Transilvania University of Brasov 2 (51), Series IV: Philology and Cultural Studies: $249-56$.

Coxon, Ann. 2010. Louise Bourgeois. London: Tate Publishing.

Creed, Barbara. 1993. "Medusa's Head: The Vagina Dentata." In The Monstrous-Feminine: Film, Feminism and Psychoanalysis, edited by Barbara Creed, 105-121. London: Routledge.

Delaney, Janice, Mary Jane Lupton, and Emily Toth. 1976. The Curse: A Cultural History of Menstruation. New York: EP Dutton and Co. Inc.

Frist Art Museum. 2009. "Paint Made Flesh Exhibition at the Frist Center." Filmed 31 March 2009 at Frist Art Museum, Video, 05:12.

Held, Julius S., and Donald Posner. 1971. Seventeenth and Eighteenth Century Art, Baroque Painting, Sculpture and Architecture. New York: Prentice Hall/H.N. Abrams.

Irigaray, Luce. 1980. "When Our Lips Speak Together.” Translated by Carolyn Burke. Signs 6 (1), Women: Sex and Sexuality, Part 2 (Autumn): 69-79.

. 1985. This Sex Which Is Not One. Ithaca New York: Cornell University Press.

Jones, Amelia, and Tracey Warr. 2012. The Artist's Body. London; New York, NY: Phaidon. 
Levin, Gail. 2007. Becoming Judy Chicago: A Biography of the Artist. lst ed. New York: Harmony Books.

Longhurst, Robyn. 2000. Bodies: Exploring Fluid Boundaries. New York: Routledge.

Lupton, Mary Jane. 1993. Menstruation and Psychoanalysis. Urbana: University of Illinois Press.

MacMillian, Duncan. 2008. "Blood Ties.” Modern Painters, May 2008.

Maple, Sarah. 2010. “Artist Statement 2010-2012.” Accessed July 3, 2013. http:// www.sarahmaple.com/mixedmedia.htm.

Read, Sara. 2013. Menstruation and the Female Body in Early Modern England. Basingstoke: Palgrave Macmillan.

Rosewarne, Lauren. 2012. Periods in Pop Culture: Menstruation in Film and Television. Lanham, MD: Lexington Books.

Stiles, Kristine. 1993. "Between Water and Stone, Fluxus Performance: A Metaphysics of Acts," In In the Spirit of Fluxus: Published on the Occasion of the Exhibition, edited by Elizabeth Armstrong et al., 64-99. Minneapolis: Walker Art Center.

Stiles, Kristine, and Peter Selz. 2012. Theories and Documents of Contemporary Art: A Sourcebook of Artists' Writings. Berkeley, CA: University of California Press.

Yoshimoto, Midori. 2005. Into Performance: Japanese Women Artists in New York. New Brunswick, NJ: Rutgers University Press.

Open Access This chapter is licensed under the terms of the Creative Commons Attribution 4.0 International License (http://creativecommons.org/licenses/ by $/ 4.0 /$ ), which permits use, sharing, adaptation, distribution and reproduction in any medium or format, as long as you give appropriate credit to the original author(s) and the source, provide a link to the Creative Commons license and indicate if changes were made.

The images or other third party material in this chapter are included in the chapter's Creative Commons license, unless indicated otherwise in a credit line to the material. If material is not included in the chapter's Creative Commons license and your intended use is not permitted by statutory regulation or exceeds the permitted use, you will need to obtain permission directly from the copyright holder.

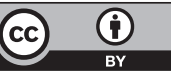

